\title{
El interés superior del menor prohíbe la restricción del derecho de adopción a las solas parejas de personas heterosexuales
}

\section{Comentario a la Sentencia C-683/15 de la Corte Constitucional de Colombia y una brevísima reflexión sobre el estado de la cuestión en Italia. (Artículo 44 de la Constitución de Colombia; artículos 64, 66 y 68 de la Ley 1098 de 2006; artículo I de la Ley 54 de I990)}

\section{Roberto de Felice}

Colombia, a pesar de la oposición de un legislador conservador, lentamente ha adecuado su ordenamiento jurídico con miras a reconocer a las parejas homosexuales el derecho de casarse, de adoptar conjuntamente y de adoptar el hijo de la pareja.

Es necesario partir de la Ley 54 de 1990 , que, a pesar de que indicaba en su artículo i que su alcance se limitaba a las uniones heterosexuales, establecía un régimen jurídico de protección para las uniones maritales de hecho. Concretamente, las uniones familiares no conyugales, después de dos años, asumen ex lege el estatus de uniones de hecho y los relativos (limitados) derechos, generalmente de carácter patrimonial. La ley, en efecto, se limita a establecer que

Fecha de recepción: 4 de abril de 20I6. Fecha de aceptación: 9 de octubre de 2016.

Para citar el artículo: R. DE FeLice, "El interés superior del menor prohíbe la restricción del derecho de adopción a las solas parejas de personas heterosexuales", Revista de Derecho Privado, Universidad Externado de Colombia, n. ${ }^{\circ}$ 3I, julio-diciembre de 20I6, 385-408. DoI: http:// dx.doi.org/10.18601/or234366.n31.15

Trad. del italiano: Francy Kellner.

* Abogado del Estado, Italia. Ex magistrado ordinario, con funciones de Ministerio Público. Socio y miembro del Consejo Ejecutivo de la Avvocatura per i diritti LGBT-Red Lenford. Contacto: luciosestiolaterano@gmail.com 
existe una comunidad de bienes sobre los frutos de su trabajo, pero la figura de la unión marital de hecho ha sido evocada por otros textos legislativos en otros sectores del ordenamiento. En particular, y a los fines que aquí interesan, el Código de la Infancia y la Adolescencia prevé para los compañeros permanentes la posibilidad de solicitar la adopción conjunta de un niño o niña, o la opción de adoptar los hijos de la pareja (en este caso, con exclusión de cualquier efecto extintivo del parentesco con el otro progenitor biológico, pero con la adquisición de parentesco de una tercera familia, la del adoptante). También en el caso del Stepchild Adoption el adoptante deberá demostrar su idoneidad parental. Es admitida la adopción de los hijos mayores sólo en el caso de que la convivencia de dos años haya iniciado antes del cumplimiento de la mayoría de edad por parte de aquellos; también se admite la adopción por parte de una persona no casada ni sujeta al régimen de la Ley 54 de 1990.

Intuitivamente, a partir de la Ley 1098 de 2006, la adopción no podía ser realizada por parte de uniones homosexuales, ya fuera de manera conjunta o en la forma de Stepchild Adoption, por no estarles autorizado el matrimonio ni ser destinatarias de la Ley 54 .

El I8 de febrero de 2007, no obstante, la Corte Constitucional colombiana, en su Sentencia C-075/o7, considerando lesiva de la dignidad humana garantizada por la Constitución la ausencia de toda protección para las uniones homosexuales estables, declaró la inconstitucionalidad de la Ley 54 de 1990 en aquellas partes en que no se aplicaba a estas uniones; con la posterior Sentencia C-8 I i/o7, y por las mismas razones, les extendió los beneficios de la seguridad social; con la Sentencia C-336/o8 extendió al compañero permanente supérstite la pensión de sobrevivientes, siempre en nombre de la dignidad humana y en ausencia de justificación racional para una discriminación en este sentido. Mediante Sentencia C-029/o9 se extendió a estas uniones lo dispuesto en 42 disposiciones (incluyendo aquella de la inexistencia del deber de declarar en contra de la pareja). Por lo tanto, la Corte Constitucional colombiana (a diferencia de las vagas intenciones expresadas por la Corte Constitucional italiana, en el fallo I38/IO, de verificar punto por punto si el ordenamiento vulnerase el principio de igualdad con respecto a las uniones homosexuales) ha procedido rápidamente a ampliar a estas uniones y a los compañeros permanentes que integran las mismas los derechos no reconocidos por la legislación en vigor.

Entrando al campo del derecho de familia, con la histórica decisión de la Sentencia C-577/I I, del 26 de julio, la Corte acogió en parte la demanda de declaratoria de inconstitucionalidad del artículo i 3 c.c. colombiano, que define el matrimonio como unión heterosexual. La decisión establece que la categoría de la orientación sexual es un criterio sospechoso de discriminación, que la Constitución protege todo tipo de familia, y que la heterosexualidad (como la consanguinidad) no es un atributo necesario de la institución familiar. 
Por otro lado, a pesar del reconocimiento a tales parejas de figuras como la unión marital de hecho y de muchas otras instituciones (seguridad social, asistencial, pensión alimentaria) dispuesto por la propia Corte, subsistía una marcada diferencia de tutela en relación con la familia matrimonial heterosexual. Así que, o bien el legislador debía extender a estas uniones el matrimonio, o bien debía crear una institución ad hoc que confiriese a las uniones homosexuales derechos próximos a los derivados del matrimonio. Si así no hubiera procedido a más tardar el 20 de junio de 2013 , esas parejas quedarían facultadas para formalizar ante notario o ante un juez un "vínculo contractual" que produjese el efecto de eliminar este déficit de protección. El plazo expiró inútilmente. Debido al limbo jurídico en que por esta sentencia había quedado la posibilidad de contraer "matrimonio" por parte de las parejas homosexuales luego de vencido el término concedido al Congreso para legislar sobre el matrimonio homosexual, y de la poca claridad de la Corte sobre la naturaleza del vínculo que, so pena de la inactividad del legislador, las parejas homosexuales podían contraer, la praxis llevó a la siguiente situación: algunos jueces celebraban matrimonios, mientras que los notarios, por temor a sanciones disciplinarias por parte de la Procuraduría General de la Nación (que curiosamente es una entidad de derecho público que tiene como función la guarda de los derechos fundamentales, pero en el momento de redactar este artículo tiene como procurador a un funcionario extremadamente "conservador"), sólo formalizaban un acuerdo solemne que no tenía los efectos del matrimonio ${ }^{\mathrm{I}}$. Entretanto, con Circular del 2 de marzo de 20 r6 (del todo opuesta a la conocida circular del Gobierno italiano), la Registraduría Nacional del Estado Civil dispuso la transcripción de los matrimonios de uniones homosexuales celebrados en el extranjero en modo válido según la lex loci actus. Posteriormente, una nueva decisión de la Corte puso punto final a la discusión sobre el matrimonio homosexual. Se trata de la Sentencia SU-2 I4/r6, resultado de las muchas acciones de tutela instauradas en contra de los notarios que se negaron sistemáticamente a celebrar contratos de matrimonio. En esta decisión la Corte consideró el actuar de los notarios como discriminatorio de las parejas del mismo sexo y los obligó por lo tanto a unir a las parejas por medio del vínculo del matrimonio. La ratio decidendi de la sentencia resulta obligatoria para todos los jueces y notarios, de manera que ninguno de estos funcionarios puede negarse a unir en matrimonio a las parejas del mismo sexo.

Incluso, con referencia a la transcripción del acta de nacimiento de dos menores como hijos de una pareja homosexual que había recurrido a la maternidad por sustitución en California, la Corte Constitucional colombiana, con ocasión 
de la revisión de una acción de tutela², mediante Sentencia SU-696/I 5, del I 2 de noviembre, confirmó por vía de revisión (art. 86 C. Política) la decisión del Tribunal de Medellín que había acogido la reclamación de la pareja contra la denegación de transcripción, acto administrativo susceptible de esta acción de tutela por ser violatorio de derechos fundamentales: el derecho de los menores a no ser separados de la familia de origen, que ostenta el carácter de fundamental de conformidad con el artículo 44 superior, no puede ser interpretado en modo arbitrario y discriminatorio, como tampoco pueden serlo sus derechos a adquirir la nacionalidad colombiana y la capacidad jurídica (que incluye la capacidad para ser titulares de la relación de filiación); en particular, no pueden serlo con fundamento en la orientación sexual de los padres (declarados además como tales en acto auténtico y apostillado que debía ser reconocido por los órganos administrativos de registro, los cuales, en cambio, se habían excusado en la inexistencia de disposiciones que permitieran la inscripción). Por lo tanto, la Corte ordenó la transcripción respectiva. Es interesante señalar que la Registraduría Nacional del Estado Civil, en el curso del proceso, refirió a la Corte que en cumplimiento del fallo del Tribunal de Medellín ya había procedido a adecuar el formulario de registro sobre el estado civil, permitiendo la inscripción en las casillas "padre" y "madre" aun de personas del mismo sexo.

En materia de Stepchild Adoption se señalan dos casos. En el primero, mediante Sentencia T-6r7/r4, del 28 de agosto, la Corte Constitucional colombiana modificó la decisión del Tribunal Superior de Antioquia en virtud de recurso de apelación de una acción de tutela, interpuesto por una pareja de dos mujeres que -previo acuerdo notarial celebrado en Alemania contentivo del consentimiento sobre la creación de un vínculo jurídico entre la madre no biológica y el niño que nacería de una futura intervención de fecundación asistida-, habiendo solicitado esta adopción particular, no la había obtenido debido a la negativa del Defensor de Familia local (competente para la fase preliminar del procedimiento en vía

2 Típico del derecho de los países de Centro y Suramérica, el amparo es un procedimiento sumario, confiado al conocimiento del juez ordinario, de protección ante los actos y omisiones de los poderes públicos que atenten contra un derecho fundamental. En Colombia es denominado acción de tutela, prevista en el artículo 86 de la Constitución, e implica que después de su apelación el juez deba enviar lo actuado a la Corte Constitucional para su eventual revisión, la cual se pronuncia discrecionalmente, sin declarar la ineficacia de una norma (lo que la diferencia de la acción pública o popular de inconstitucionalidad), sino proveyendo en el caso concreto. La ratio decidendi de una acción de tutela en sede de revisión de la Corte Constitucional obliga a todas las autoridades en casos similares. Al respecto véase, p. ej., Arroyo Moreno, J. Á., "El origen del juicio de amparo", en Moreno-Bonett y González Domínguez (eds.), La génesis de los derechos humanos en México, México, Unam, 2006, 43-6I. En general sobre los antecendentes, y en especial sobre el derecho argentino, véase en italiano, p. ej., Frosina, L., "L'acción de amparo nella esperienza costituzionale argentina", en federalismi.it-Focus America Latina I, 20 I4, I-45, 6, disponible en: http://www.federalismi.it/document/I 5 I220I4I938 Io.pdf Para el caso colombiano sigue siendo un libro de referencia sobre los inicios de la figura en el derecho nacional de este país el escrito por Osuna, N., Tutela y amparo: derechos protegidos, Bogotá, Universidad Externado de Colombia, I 998. 
administrativa). Los jueces concedieron la acción de tutela únicamente por la violación del debido proceso, sin pronunciarse de fondo, en primera instancia y en apelación; pero fueron luego censurados por la Corte Constitucional. Citando la decisión de la Sentencia C-075/o7 y una vez acreditada la unión marital de hecho de la pareja y verificado el requisito de la convivencia de dos años previsto por el Código de la Infancia y la Adolescencia, la Corte consideró además violado el derecho de la pequeña Lakmé a una familia que cuidara de ella.

En sentencia posterior, la C-07I/I5, del i 8 de febrero, la Corte acogió la demanda dirigida a declarar la inconstitucionalidad de los artículos 64, 66 y 68 del Código de la Infancia y la Adolescencia, así como del artículo i de la Ley 54 de 1990 en cuanto a la Stepchild Adoption, instrumento indispensable para la continuidad afectiva y educativa del niño criado por pareja homosexual, cuyos derechos serían puestos en peligro en caso de muerte del padre biológico; pero la rechazó en cuanto a la adopción conjunta, considerando que el principio de igualdad para las parejas homosexuales no resultaba violado en cuanto el legislador había querido dar importancia al principio de dualidad sexual de los padres. Se observará en cambio cómo, para evitar conflictos y "blindar" el pronunciamiento, en la decisión aquí comentada se admite la adopción conjunta con fundamento en la violación de otro principio constitucional: el del interés superior del menor.

\section{El caso en examen}

Mediante Sentencia C-683/ı 5, del 4 de noviembre, depositada en la Secretaría el i 5 de febrero del año siguiente, la Corte Constitucional de Colombia declaró la inconstitucionalidad parcial del artículo 68 de la Ley ro98 de 2006, Código de la Infancia y la Adolescencia. La norma en particular, al establecer los requisitos de los adoptantes, disponía que pudieran iniciar el proceso de adopción: personas solteras, viudas o separadas, los cónyuges (hay que especificar que en la época de la aprobación de la ley este concepto podía referirse sólo a una pareja de esposos heterosexuales), así como las uniones maritales de hecho que hubieran cohabitado ininterrumpidamente al menos por dos años (que en la época de aprobación de la ley sólo podía entenderse como una unión heterosexual). Esta ley también preveía en el numeral 5 del citado artículo la posibilidad de adoptar al hijo del otro cónyuge o compañero permanente (en este último caso, después de dos años de convivencia ininterrumpida con el menor).

Se acudió a la Corte, de acuerdo con el numeral 4 del artículo 24I de la Constitución, en ejercicio de dos acciones de inconstitucionalidad, luego acumuladas, instauradas por ciudadanos que alegaban la inconstitucionalidad de la norma. En particular, en el primer recurso se acusaba lo dispuesto en el citado artículo 68 y en el artículo i de la Ley 54 de i990, que tuvo la precaución de definir en términos necesariamente heterosexuales las uniones conyugales de 
hecho. Los demandantes, miembros de la Clínica Jurídica del Instituto de Teoría General del Derecho de la Universidad de Medellín, señalaron como violados los artículos I 3,42 y 44 de la Constitución de Colombia, así como los artículos 2 y 3.I de la Convención sobre los Derechos del Niño y el artículo iq de la Convención Americana sobre Derechos Humanos. En efecto, de la lectura de las normas acusadas resultaba la imposibilidad de la adopción para las uniones homosexuales. Los demandantes no sólo consideraron que no había ninguna razón objetiva para excluir a las uniones maritales de parejas homosexuales el acceso a la adopción, sino también que la exclusión para ellas de tal figura jurídica perjudica el derecho mismo de los menores abandonados a tener una familia al reducir el universo de las posibles familias adoptantes, socavando así su derecho fundamental a tener una familia. La Corte Constitucional, después de haber rechazado solicitudes de recusación formuladas por parte del Procurador General de la Nación contra dos de sus magistrados, dio curso a las acciones. En particular, invitó a las facultades de sociología, psicología, salud pública, ciencias de la salud y medicina de algunas universidades del país, junto al Ministerio de Educación, al Ministerio de Salud y al Instituto Colombiano de Bienestar Familiar (ICBF), a presentar sus conclusiones en relación con los efectos que podría tener sobre los menores el hecho de ser adoptados por parejas del mismo sexo. Fue también invitado a rendir su concepto al Alto Comisionado de las Naciones Unidas en Colombia. La motivación de la decisión tomada por la Corte parte de un informe del Ministerio de Salud. Según dicha autoridad, no existe ninguna prueba de que la adopción por parte de uniones maritales del mismo sexo haga surgir un riesgo para la salud física o mental de los menores, porque la literatura y la práctica pertinentes a este respecto lo excluyen. Por el contrario, la orientación sexual de los padres es indiferente para el desarrollo cognitivo y social de los menores e incluso, en muchos casos, como en la adopción de menores de alto riesgo, esta forma de adopción puede contribuir a su bienestar. El Ministerio cita las conclusiones de la Academia Americana de Pediatría (American Academyc of Pediatrics - AAP), que examina la literatura disponible luego de más de treinta años de investigación, según la cual la orientación sexual de los padres no tiene efecto sobre la salud y el bienestar de sus hijos menores, los cuales, incluso, pueden sufrir una mayor lesión de su bienestar por las desigualdades de trato jurídicas y por la hostilidad social que puede derivar de regulaciones restrictivas para las parejas del mismo sexo. El Ministerio también cita una investigación realizada por la Facultad de Desarrollo Infantil y Educación de la Universidad de Ámsterdam en el año 2005, al igual que otras fuentes relevantes.

El Procurador General de la Nación, al formular sus observaciones, no negaba la inexistencia de riesgos hipotéticos, pero pedía el rechazo de las demandas sobre la base del consolidado concepto de familia como institución fundamental de la sociedad. La familia es una realidad sociológica aun antes que jurídica, pero el Procurador pedía a la Corte Constitucional resolver los problemas debidos 
a la interpretación relativa de las normas denunciadas en el sentido de reservar únicamente a las parejas heterosexuales la posibilidad de solicitar la adopción.

El Defensor del Pueblo apoyó la demanda. El IсBF, por el contrario, se opuso en consideración a la notable diferencia entre las uniones maritales homosexuales y las heterosexuales. Intervinieron en el estudio del caso seis facultades de derecho de diversas universidades, las cuales, con excepción de la de una universidad católica, adherían a la posición de las demandas. En particular, la única facultad de derecho discrepante se apoyó en la "verdad antropológica" que sostiene que hombres y mujeres son complementarios y en el hecho biológico de que la reproducción depende del hombre y de la mujer: por lo tanto, esta sería la realidad social según la cual los niños necesitan de una madre y de un padre, no sin mencionar que según un -aislado- estudio sociológico, los niños cuidados en una relación estable entre el padre-hombre y la madre-mujer tendrían un mejor rendimiento académico, una mejor salud emocional y bajos índices delictivos. Igualmente participaron en el estudio varias asociaciones, todas ellas presentando un concepto favorable a la aceptación de la petición de inconstitucionalidad.

El Procurador General, en cambio, concluyó que la petición de inconstitucionalidad debía ser desestimada. Para lo cual invocó una sentencia anterior de la Corte, la C-577/ I I, que, sin embargo, aun habiendo calificado como familias a las uniones maritales formadas por personas del mismo sexo, no había afrontado el tema de la adopción.

\section{La ausencia de cosa juzgada constitucional}

Preliminarmente la Corte aborda la cuestión del contraste entre la declaratoria de inconstitucionalidad planteada y la solución de la propia Sentencia C-07 I/ I 5 (favorable solamente a la Stepchild Adoption). Se recuerda que la Corte en aquella ocasión declaró como inconstitucionales las normas que impedían a las uniones maritales formadas por personas del mismo sexo la adopción del hijo de la pareja, pero no las normas que exigían la adopción conjunta de un hijo que no fuese hijo biológico de uno de ambos. La Corte resuelve la aparente contradicción haciendo un llamado a sus principios en materia de cosa juzgada constitucional. La Corte Constitucional de Colombia, en virtud del principio de separación de poderes, como se establece en el articulado de la Constitución, declara la inexequibilidad (ineficacia) de las normas que contravengan la Constitución. Ahora bien, si una norma es declarada inconstitucional en sentido absoluto, evidentemente subsiste un vínculo de cosa juzgada porque en ningún otro caso la Corte Constitucional podrá ocuparse de una norma declarada totalmente ineficaz. Por el contrario, cuando la Corte declara la inconstitucionalidad parcial de una norma, como lo fue en el caso de la Sentencia C-07 I/ I 5, condiciona su eficacia a la interpretación constitucionalmente orientada que la Corte le dé, y ello hace posible examinar la misma norma bajo otros aspectos de constitucionalidad. En el 
caso bajo examen de la decisión que se comenta, la Corte precisa que no aborda la cuestión de constitucionalidad de la norma que impide la adopción conjunta a las personas homosexuales bajo la perspectiva de la discriminación de la pareja de personas homosexuales, sino que la examina bajo el perfil del principio del interés superior del menor. Este principio está contenido en la Declaración de los Derechos del Niño de I989, que fue ratificada por Colombia mediante la Ley I 2 de I99I, y en aquel instrumento se extiende a todas las medidas que conciernan al menor, sean judiciales o administrativas. Esto aparece consagrado por el artículo 3 numeral i I de la Declaración y constituye no sólo un derecho subjetivo de cada menor, sino también una regla procedimental y un canon fundamental de interpretación de las normas vigentes. En este punto, conviene tener en cuenta el artículo 44 de la Constitución de Colombia, que enuncia como derechos fundamentales de los niños el derecho a la vida, a la integridad física, a la salud, a la seguridad social, a la alimentación equilibrada, al nombre y a la ciudadanía, a tener una familia, a no ser separados de ella, al cuidado, al amor, a la educación, a la cultura, a la recreación y a la libre expresión de sus opiniones. El artículo 44 además remite a los demás derechos consagrados por las leyes y los tratados internacionales ratificados por Colombia, entre los que precisamente se encuentra la Declaración de los Derechos del Niño. En este marco, las autoridades de Colombia tienen la obligación de mitigar las condiciones en que se encuentre el titular de un derecho constitucional al momento de tomar una decisión en orden al derecho mismo. Ahora, tanto el artículo 44 de la Constitución como la Declaración sobre los Derechos del Niño consagran el derecho fundamental de los menores a tener una familia y a no ser separados de ella. Ello implica, según la misma Corte Constitucional, precisamente en la ya citada Sentencia C-07I/ I 5, que el derecho a tener una familia no está referido únicamente a la comunidad biológico-natural vinculada al proceso de gestación, sino que se extiende también a personas no vinculadas por consanguinidad. Además, ya desde la Sentencia T-2 I 7/94 se reconoce que la plena protección constitucional de la familia biológica no implica que la familia de hecho no sea objeto de protección y reconocimiento constitucional, y como consecuencia, el derecho del menor a tener una familia no implica que esta deba ser necesariamente la propia familia biológica, pudiendo ser también una de las muchas otras estructuras familiares existentes, como la familia recompuesta, la familia extendida, entre otros muchos otros casos ${ }^{3}$. El Estado tiene el preciso deber de intervenir en caso de riesgo o de abandono del menor por parte de la propia familia, y al mismo tiempo de proteger los vínculos familiares ya consolidados. Una institución particular del

3 Sobre el concepto de familia en el constitucionalismo latinoamericano véase, p. ej., EsBorraz, D. F., "El concepto constitucional de familia en América Latina. Tendencias y proyecciones", Revista de Derecho Privado, Universidad Externado de Colombia, n. ${ }^{\circ}$ 29, 2015 , I 5-55. 
derecho civil colombiano es la de la llamada familia de crianz $a^{4}$, es decir, aquella constituida por uno o más menores y por una pareja que no está biológicamente vinculada a ellos, donde, a raíz de situaciones de custodia temporal o incluso de sólo cuidado espontáneo del menor o los menores, viene a forjarse un vínculo de afecto que tiene el mismo significado social que la filiación biológica. La adopción es una de las medidas con las cuales el Estado asegura el derecho del menor a una familia. Ello para suplir las relaciones de filiación que nunca se constituyeron o que han dejado de existir, por ejemplo, por la muerte o la total incapacidad de los padres. Principio fundamental de la adopción es también aquí el interés superior del menor, por lo que la adopción sirve para dar una familia a un niño y no para dar un niño a una familia. Este derecho puede realizarse en el seno de cualquier tipo de familia protegida por la Constitución, tanto en aquellas familias constituidas por vínculos jurídicos como en las de hecho. Más aún, precisamente en aplicación del artículo 7 de la Constitución, que reconoce y protege la diversidad étnica y cultural de la nación, no existe un tipo único privilegiado de familia, sino un evidente pluralismo en cuanto a los diferentes vínculos que le dan origen, naturales o jurídicos, uno de los cuales es el modelo de la familia fundada por parejas del mismo sexo, cuya protección constitucional fue reconocida a partir de la Sentencia C-577/I i de la misma Corte.

\section{Una aproximación al derecho comparado}

En este punto la Corte realiza una profunda digresión examinando el derecho comparado, particularmente la circunstancia de que gran parte de los países europeos, de Norteamérica y de Oceanía reconocen alguna forma de adopción por parte de parejas del mismo sexo, ya sea de manera conjunta o como adopción del hijastro.

Así, en el contexto latinoamericano, ejemplos de legislación que permiten este tipo de adopción se encuentran en México, Argentina, Uruguay y Brasil. La Corte recuerda el papel fundamental desempeñado por la jurisprudencia y por los numerosos cuerpos legislativos. De igual modo, recuerda que en estos corpus legislativos y en la jurisprudencia siempre se ha abordado el problema de la adecuada protección del interés superior del menor, el cual, unánimemente, no se ha considerado lesionado por la circunstancia de que la adopción sea realizada por parte de una pareja homosexual. Lo que realmente importa es la capacidad de la pareja para hacerse cargo del cuidado del menor que necesita ser acogido en ella.

La Corte realiza un estudio de derecho comparado deteniéndose, en primer lugar, en la decisión de la Corte Interamericana de Derechos Humanos (CIDH) del 24 de febrero de 2012, caso Atala Riffo contra Chile. Como se recordará, la

4 Ver Corte Constitucional,Sentencia T-606/r3 3 http://www.corteconstitucional.gov.co/relatoria/ 2013/t-606-1 3.html 
demandante había dado a luz tres hijas durante su matrimonio. Después de la separación había obtenido la custodia de estas, pero después de que su nueva compañera comenzara a convivir con ella y con las menores, las autoridades judiciales de ese país, a instancia del padre, le habían retirado la custodia, por orden, no de los jueces de instancia, sino de la propia Corte Suprema de Justicia, que motivó su decisión en el potencial perjuicio que las niñas podrían sufrir en razón de su convivencia con una madre homosexual, y del -por la Corte considerado- egocentrismo de la madre, consistente en haber dado inicio a una nueva convivencia, homosexual, en el mismo hogar familiar en el que cuidaba de sus hijas, no sin mencionar el perjuicio sufrido por las menores por el hecho de no vivir en una familia tradicional.

La cidH declaró la responsabilidad del Estado chileno por haber perjudicado la vida privada de la demandante y de sus hijas en razón de un acto discriminatorio, declarando que no podían ser admisibles inferencias, presunciones, estereotipos y consideraciones generales sobre las características personales de los padres o sus preferencias culturales respecto a algunos conceptos tradicionales de la familia, y que el interés superior del menor no puede ser utilizado para fundamentar una discriminación contra la madre o el padre en razón de la orientación sexual de alguno de ellos.

En particular, la cidH menciona los informes científicos de dos expertos que habían señalado que la convivencia de menores con padres homosexuales no daña ni perjudica en sí su desarrollo emocional y psicológico; que según la doctrina pedagógica y psicológica común, las habilidades para ser padres en los casos de parejas heterosexuales son equivalentes en las parejas homosexuales, y que el desarrollo armónico y el bienestar emocional de los niños y niñas criados por madres lesbianas eran absolutamente comparables con los de menores criados por padres heterosexuales. En general, la orientación sexual resulta irrelevante para la formación de vínculos afectivos de los menores con sus padres y no perjudica el desarrollo de los menores en función de su género, tanto en lo que respecta a la propia percepción de sí mismo, como hombre o como mujer, como en cuanto al rol de género y a su propia orientación sexual.

Junto a este precedente, la Corte Constitucional cita la resolución del Tribunal Europeo de Derechos Humanos (TEDH) en el caso X contra Austria, donde se discutía sobre la aplicación del artículo I 82 párrafo 2 ABGB, que excluía la adopción del hijo del compañero permanente por parte de una persona que fuera del mismo sexo del padre o la madre biológica en ausencia de una relación biológica con el menor. La Corte de Estrasburgo, en particular, declaró que las diferencias de tratamiento basadas en el sexo o la orientación sexual están sometidas a un margen de apreciación limitado por parte de los distintos Estados miembros del Consejo de Europa.

En el caso E.B. contra Francia, la misma Corte comprobó que las autoridades competentes, en un caso de adopción por parte de una persona no casada, ha- 
bían fundado su denegación básicamente en la falta de un referente paterno en la familia de la solicitante y en la falta de un compromiso, por parte de su compañera, de participar del proceso de adopción; por lo tanto, sustancialmente, la homosexualidad de la solicitante generó el rechazo de la solicitud, sin haber sido evaluadas sus capacidades de crianza.

En el caso Gas et Dubois contra Francia, la jurisprudencia de la Corte de Estrasburgo se mantuvo en la idea de que, en el concepto de familia como protegido por el artículo $8 \mathrm{CEDH}$, se encuadra perfectamente también la familia constituida por una pareja homosexual, y que toda limitación a los derechos de las parejas de esta naturaleza tiene que estar debidamente motivada y justificada por el Estado miembro que la hubiere realizado, debiendo este indicar también el objetivo que procuraba perseguir con tal limitación; así las cosas, la carga de la prueba corresponde exclusivamente al Estado. En el caso particular, el gobierno francés no había presentado ningún argumento específico o estudio científico que demostrase que una familia con dos padres del mismo sexo no pudiera hacer frente a las necesidades de un menor; al contrario, había reconocido que, en concreto, parejas del mismo sexo bien podían considerarse adecuadas para esta tarea y que la legislación que era puesta en entredicho tenía el único fin de mantener en vida el tradicional concepto de que la adopción imita la naturaleza y de que en cualquier caso un menor debe tener padres de distinto sexo, aunque sean adoptivos.

En Estados Unidos, en cambio, todos los Estados permiten la adopción de la persona no casada sin que sea relevante la orientación sexual de la misma; en veinticuatro estados de la Federación y en el Distrito de Columbia también se permite la adopción posterior, es decir, la adopción del hijo biológico o adoptivo del propio compañero o compañera; en veintitrés estados y en el Distrito de Columbia también pueden las parejas homosexuales recurrir a la adopción conjunta. La Corte recuerda el caso Evan, decidido por una corte del Estado de Nueva York, que en 1992 concedió la Stepchild Adoption a la compañera de la madre biológica de un niño de seis años. La Corte de Nueva York afirmó que la proporción de hijas lesbianas no varía en función de la orientación sexual de las madres y que no hay diferencias significativas entre los hijos de madres lesbianas y los de madres heterosexuales; todo ello de la mano de estudios científicos.

En el caso de la adopción de Caitlin, otra corte del Estado de Nueva York destacó la ausencia de preclusiones legales a la adopción por parte de un progenitor homosexual, citando aquí también estudios científicos prestigiosos e independientes que niegan perjuicios para los hijos que cohabitan con padres homosexuales. Una decisión posterior de la Corte Suprema del Estado de Arkansas, en I999, anuló una decisión del Comité Ejecutivo de la Agencia para la Prevención del Abuso y el Abandono de la Niñez del mismo estado, la cual prohibía que se diera la custodia de menores a familias donde hubiera personas homosexuales. En el caso concreto, los actores eran adultos y homosexuales; pero la peor torpeza de la norma consistía en que incluso la presencia de un hermano menor 
homosexual dentro del ámbito familiar habría impedido la custodia del niño por esa familia. En su razonamiento, la Corte Suprema sostuvo también aquí que no hay correlación alguna entre la orientación sexual de los padres y el desarrollo armónico regular integral de los hijos.

En el caso Gill, que fue juzgado por el Tribunal de Apelaciones del Tercer Distrito de la Florida, una ley de 1977 que prohibía expresamente la adopción a parejas homosexuales fue declarada inconstitucional por ser contraria a la Constitución del Estado. En el caso concreto, los actores, padres de crianza de niños abusados, habían pedido sin éxito su adopción, luego de haber cesado la patria potestad de los padres biológicos. Se les concedió razón tanto en primera instancia como en apelación. Ambas decisiones sostuvieron la ausencia de diferencias de adaptación y desarrollo emocional e integral de los niños confiados a padres homosexuales respecto a los confiados a padres heterosexuales, con base en conclusiones de la Asociación Americana de Psicología (American Psychological Association) y de los psiquiatras y pediatras del mismo Estado de la Florida, como también de la Asociación Nacional de Trabajadores Sociales (The National Association of Social Workers).

Sigue luego el examen de otra decisión, DeBoer v. Snyder del 2 I de marzo de 20I4, emanada por un juez federal de Michigan. De hecho, la causa se refería a la constitucionalidad de una ley del estado que prohibía los matrimonios de parejas del mismo sexo. No obstante, el juez analizó también los aspectos relativos a la supuesta incapacidad de los homosexuales para ser buenos padres. La decisión es particularmente importante porque el juez se pronunció sobre el único estudio contrario a la adopción por parte de parejas homosexuales, el estudio del Dr. Mark Regnerus. El testimonio del autor de este estudio se consideró poco creíble, visto que su libro había sido financiado por un instituto conservador, que tenía un programa de discriminación a la población homosexual y que el autor se había limitado a proporcionar las conclusiones deseadas por parte de sus financiadores. En particular, el estudio carecía de credibilidad en cuanto equiparaba la situación del menor educado desde el nacimiento por una pareja homosexual a la del menor que hubiera vivido con un progenitor que hubiera establecido una relación homosexual por un período de tiempo determinado. El estudio fue realizado precipitadamente por insistencia de los financiadores. Vale añadir, por parte de quien escribe, que la decisión federal de Michigan fue anulada en apelación pero confirmada por la Corte Suprema el 26 de junio de 2015 en el conocido caso Obergefells.

Por lo que respecta a México, la Suprema Corte de Justicia de la Nación, en fallo del i6 de agosto de 20Io, rechazó el recurso del Procurador General destinado a la declaración de inconstitucionalidad de los nuevos incisos de los artículos I46 y 39r del Código Civil del Distrito Federal que admitían tanto el matrimonio como la adopción por parte de parejas del mismo sexo. La Corte consideró que la orientación sexual es simplemente una de las opciones que se 
presentan en la naturaleza humana, y que como tal forma parte de la autodeterminación y del libre desarrollo de la personalidad, así como que resulta degradante considerar a un ser humano nocivo para el desarrollo de un menor sólo en razón de su orientación, la cual en nada afecta el interés superior de este.

Por su parte, el 6 de noviembre de 2012 el Tribunal Constitucional español rechazó las objeciones formuladas por los diputados del grupo del Partido Popular contra la Ley I 3 de 2005, que modificó el Código Civil extendiendo a las parejas de personas del mismo sexo el derecho a contraer matrimonio. El Tribunal Constitucional trató como aspecto secundario el de la adopción de menores por parte de parejas del mismo sexo, declarando en particular que el interés del menor adoptado por una pareja casada homosexual o por una pareja casada heterosexual debe ser tutelado de conformidad con el artículo 39 de la Constitución, y que este interés debe ser protegido en cada caso concreto en función de la evaluación a la que se someten los posibles adoptantes, con independencia de su orientación sexual; de modo que la protección integral de los hijos, en concordancia con el citado artículo 39 de la Constitución, no resulta afectada por el hecho de que se permita a los homosexuales adoptar de forma individual o con el respectivo cónyuge.

A su turno, el ro de septiembre de 2002 la Corte Constitucional de Sudáfrica reconoció el derecho de las parejas del mismo sexo a la adopción conjunta, que en el caso concreto había sido solicitada por una pareja de lesbianas a pesar de que lo prohibiera la legislación vigente, por lo que las autoridades habían dispuesto la adopción sólo respecto de una de las dos compañeras. La decisión fue objeto de impugnación en juicio y recibida para ser atendida por parte de la Corte Constitucional. Esta consideró que la exclusión de las parejas del mismo sexo de la adopción conjunta era contraria a la esencia y al propósito social de la adopción, y que la estabilidad, el compromiso, el afecto y el apoyo para el desarrollo del menor pueden ser ofrecidos por cualquier persona cualificada.

También el Tribunal Constitucional Federal Alemán, en la decisión del i 9 de febrero de 2013 relativa a la adopción sucesiva, afrontó el tema en general. La conclusión fue que no debía ser temida una amenaza para el interés superior del menor en el caso específico, porque la adopción sucesiva, como toda adopción, requiere de una evaluación individual precedente que debe considerar cualquier tipo de ventajas y desventajas individuales en concreto.

La Corte colombiana analizó asimismo la situación de Canadá, cuyas provincias tienen autonomía con referencia a la materia de adopción. Todas ellas han ampliado la adopción a las parejas homosexuales entre 1996 y 2009. La Corte alude al caso decidido con referencia a la Ley de la Provincia de Ontario en materia de Stepchild Adoption: la Corte Superior de Justicia de Ontario, constatando que la adopción del hijastro estaba cerrada a una persona del mismo sexo del padre biológico, aunque fuera su cónyuge, declaraba inconstitucionales dichas normas manifestando que no era posible imaginar un ejemplo más fla- 
grante de discriminación. Negar la protección del interés del menor a causa de la orientación sexual del solicitante era manifiestamente contrario al artículo i 5 de la Constitución de Canadá. En I 996 un caso idéntico fue analizado por la Corte Provincial de Alberta que, sin embargo, se abstuvo de decidir en razón de la intención del legislador de derogar la disposición; por último, en mayo de I999, la Corte Suprema de Canadá confirmó que era inconstitucional toda y cualquier norma que limitase el término cónyuge a una persona de sexo opuesto para efectos de la adopción. Aunque la decisión tomada recordaba la ley de Ontario, este pronunciamiento tuvo efectos de precedente para todo Canadá.

El estudio del derecho comparado permitió pues concluir que el interés superior del menor siempre ha sido discutido y analizado tanto en sede judicial como en sede legislativa, y confirmar que existe una apertura en favor de personas individuales y parejas homosexuales en orden a la posibilidad de adoptar; y en todos estos casos, siempre con el soporte de pruebas científicas, se concluyó que dicho interés no resulta perjudicado por la orientación sexual de los padres o potenciales padres.

\section{Los estudios científicos}

A continuación la Corte se ocupa de las intervenciones enviadas tanto por el ICBF como por el Ministerio de Salud, al igual que de las presentadas por: el Departamento de Psicología, el Departamento de Pediatría y la Escuela de Estudios de Género de la Universidad Nacional de Colombia; la Facultad de Ciencias Sociales y la Facultad de Medicina de la Universidad de Antioquia; el Instituto de Psicología y el Programa Académico de Sociología de la Universidad del Valle; la Universidad de Los Andes, y la Universidad Icesi. La Pontificia Universidad Javeriana se limitó a deducir que la adaptación de los niños adoptados por parejas homosexuales en el contexto colombiano sería más difícil y que este tema no ha sido debidamente estudiado. El Colegio de Nuestra Señora del Rosario adujo que en la literatura internacional se identificaban argumentos a favor y en contra del tema y que estos eran evaluados en forma diferente dependiendo del consenso social al cual cada comunidad había llegado en orden al reconocimiento de los derechos civiles de las personas. En este marco no había estudios precisos sobre el contexto colombiano. Como se ve, estas dos primeras universidades -católicas- se limitan a exigir una mayor investigación, con argumentos absolutamente contrafactuales porque no es posible estudiar la adaptación de los menores adoptados por parejas homosexuales en Colombia antes de que sea concedida en el país la posibilidad de adoptar a las parejas del mismo sexo. Se considera por quien escribe que esta es una manera de cumplir, por parte de estas instituciones, con su deber de fidelidad al magisterio católico, aunque no lo desarrollen con excesivo celo. Los departamentos de Psicología y Psiquiatría de la Universidad de Antioquia, por su parte, expresan un juicio moderadamente fa- 
vorable, aunque de nuevo concluyendo en la ausencia de una prueba concreta en el contexto colombiano. Sólo las facultades de Psicología y Medicina de la Universidad de la Sabana (vinculada al Opus Dei) parecen concluir de acuerdo con el estudio ya cuestionado por la Corte del Distrito Federal de Michigan hace pocos años. La Corte Constitucional de Colombia presenta las conclusiones de estas dos facultades, destacando en negrita o cursiva las afirmaciones que las hacen poco confiables, en particular las de la Facultad de Medicina de la Universidad de la Sabana, como por ejemplo la afirmación de que el grupo de trabajo conformado por la Asociación de Psicólogos Americanos y de la Academia Americana de Pediatría (American Academy of Pediatrics) estaría integrado por "activistas homosexuales y lesbianas indudablemente poco imparciales", o cuando señala que el comportamiento de los homosexuales "se aparta del común, lo que constituye de alguna manera una enfermedad", y que al señalar a alguien "como enfermo [...] no lo estamos discriminando".

\section{Las conclusiones del procurador general de la nación}

En marzo de 2015 el Procurador General de la Nación, después de haber recibido los informes de las academias e institutos científicos mencionados anteriormente, concluía negativamente en orden a la falta de estudios científicos de los efectos que una similar extensión del derecho a poder solicitar la adopción de menores por parte de parejas homosexuales pudiera generar en el ámbito colombiano. Además, la mayor parte de los estudios se referían a parejas de mujeres lesbianas, más bien que a parejas de hombres homosexuales, y por lo tanto no se podía considerar que fueran completos. El Ministerio Público expresó la opinión de que no había una prueba científica concluyente que permitiera a la Corte Constitucional tomar una decisión sobre la base del estado del arte. Citó un nuevo estudio de origen inglés contrario a la aceptación del recurso y, finalmente, consideró que faltaba una profundización sobre los efectos de la ausencia de una figura masculina o femenina en el transcurso de la infancia en el proceso de crecimiento y maduración del menor. La Corte resume las conclusiones del Procurador observando lo obvio: la literatura científica en la materia es abundante, aunque en ella hay posiciones antagónicas. No obstante, la mayor parte de las opiniones confirman la tesis de los demandantes bajo una perspectiva científica. La Corte Constitucional de Colombia tiene un deber preciso de tener en cuenta las pruebas científicas en el control abstracto de constitucionalidad. A partir de la Constitución de I99 I, la jurisprudencia y la misma doctrina han considerado el control de constitucionalidad de modo no abstracto y lógico-normativo, sino sustancial. El juez constitucional no puede ignorar el contexto histórico de la realidad social en el que asume sus decisiones. La Corte recuerda una decisión suya en materia de diferencia de trato con respecto a la edad de jubilación de las mujeres frente a la de los hombres, decisión en que recurrió a estudios em- 
píricos y actuariales, pudiendo así confirmar la legitimidad de tal diversidad de tratamiento.

\section{El fondo de la cuestión: ausencia de perjuicios}

Regresando al tema de fondo, la Corte considera que las pruebas recogidas son pertinentes y relevantes para la decisión. Las pruebas científicas, en su inmensa mayoría coinciden en considerar que la adopción por parte de personas del mismo sexo no perjudica el desarrollo, el bienestar, la salud física o mental de los niños, y que si alguna vez hubiera de presentarse un perjuicio, este se debería a otros factores como las reacciones de los miembros de la familia, estereotipos discriminatorios, prejuicios sociales o a las mismas discriminaciones normativas, que no tienen nada que ver con la orientación sexual de los padres. También, que el desarrollo y el comportamiento, así como la adaptación social de los hijos de parejas homosexuales, son del todo similares a los de los hijos de parejas heterosexuales; finalmente, que en proceso de adopción se debe verificar la idoneidad de los solicitantes, independientemente de su orientación sexual. En particular, es notable el informe del Ministerio de Salud, como también el del IсBF, las dos instituciones más competentes en la materia, las cuales coinciden en este punto. La Corte, debido a la vaguedad y a la falta de fuentes, duda de nuevo sobre las conclusiones proporcionadas por la Universidad del Rosario; en cuanto a la Universidad Javeriana, sus conclusiones eran no sólo particularmente ambiguas sino que también aducían apartes de estudios distintos, algunos de los cuales en últimas eran favorables a la adopción por parte de parejas homosexuales. Quienes realmente se habían pronunciado en términos negativos eran las facultades de Medicina y de Psicología de la Universidad de la Sabana. La Facultad de Psicología había aducido el estudio Regnerus, puesto en grave cuestión por deficiencias de carácter metodológico, por ejemplo en el caso decidido por la Corte del Distrito Federal de Michigan. Por otro lado, el informe de la Facultad de Medicina exponía argumentos impresentables, como que los grupos de trabajo de la AAP y de la APA estaban formados por activistas homosexuales y lesbianas sin duda poco imparciales. Estas afirmaciones ponían en evidencia que las conclusiones de esta Facultad estaban afectadas por prejuicio grave, en particular, por la argumentación denominada falacia ad personam, la cual cuestiona la veracidad de todo lo que provenga de una determinada fuente con independencia de la sustancia del asunto. Igualmente inaceptable fue la conclusión de que la homosexualidad era una enfermedad, lo que está en abierto contraste con una resolución de 1990 de la Organización Mundial de la Salud, que fuera ya objeto de examen y recibimiento en la Sentencia C-373/o2 de la misma Corte Constitucional de Colombia. 


\section{Las parejas homosexuales en la jurisprudencia de la corte}

La Corte, entonces, hace un análisis de sus propios precedentes jurisprudenciales. En Sentencia T-290/95 fue examinado el caso de un homosexual que, habiendo solicitado la adopción de una menor a él confiada y que había sido abandonada por sus padres biológicos, recibió como respuesta la anulación de la medida de custodia temporal por parte de la autoridad administrativa. La Corte, aunque rechazó el recurso, no lo hizo debido a la homosexualidad del demandante, sino tras haber comprobado que la menor se encontraba en una situación de riesgo para su seguridad y su adecuado desarrollo; no sin añadir que en Colombia no existe un único tipo familiar digno de protección, y que se reconoce de igual manera a la familia que se derive de vínculos jurídicos como a la formada por vínculos naturales o afectivos. Fundamentales para la decisión fueron los informes policiales sobre el tamaño totalmente insuficiente y el estado de degradación de la vivienda donde habitaban el demandante, su propia madre y la menor, al igual que el deterioro general, no sólo del edificio sino también de la zona donde la menor residía; asimismo, las consideraciones sobre la frecuente embriaguez del compañero del demandante. En sentencia posterior, C-8I I/or, la Corte precisó que la idoneidad moral requerida para la adopción no tiene nada que ver con las preferencias sexuales de una persona, en ese caso, al ocuparse de la constitucionalidad de una norma, contenida en el Código del Menor, que permitía solo a las parejas heterosexuales el poder adoptar conjuntamente. La Corte precisa que la idoneidad moral no se confunde con la condición de heterosexual. Sin embargo, la decisión justificó la constitucionalidad de la norma a la luz de las alusiones a la familia heterosexual contenidas en el artículo 42 de la Constitución Política. No obstante, se trataba exclusivamente de una interpretación literal, entonces dominante y hoy superada. En la posterior Sentencia C-7 I 2/ıo, la Corte, en cambio, se ocupó de la acusada inconstitucionalidad del requisito de la idoneidad "moral" exigida para los adoptantes por el artículo 68 del Código de la Infancia y la Adolescencia: concluyó claramente que la idoneidad moral no tiene nada que ver con la orientación sexual. En la misma decisión, la Corte niega que el concepto de idoneidad moral esté asociado con la condición homosexual, apoyándose en una resolución del 6 de septiembre de 20 Io del IcbF que identificó en cambio casos particularmente graves como alcoholismo, condenas por actos violentos o abusos sexuales, o el incumplimiento de la obligación alimentaria respecto de los hijos biológicos o adoptivos. La Sentencia T-276/ I 2 se ocupó de una acción de tutela interpuesta por un ciudadano extranjero contra la revocatoria de la adopción de dos niños colombianos dispuesta por el ICBF, decretada en razón de la propia homosexualidad previamente no declarada. En ese caso la Corte, que acogió el recurso, consideró que no había un nexo causal entre la falta de información sobre la orientación sexual del extranjero demandante y el riesgo presumido, en ausencia de un examen integral de la situación 
en que se encontraban los menores a la luz de las pruebas y no de las apariencias, preconcepciones y prejuicios. En la Sentencia SU-6 I 7/ I 4 una Defensora de Familia no había tramitado una solicitud de adopción concerniente a la compañera permanente de una mujer y a la hija biológica de esta última, estimando que la legislación vigente no la permitía y que la Constitución protegía solamente a la familia heterosexual. En ese caso la Corte consideró que existía un déficit de protección de la menor que amenazaba el disfrute efectivo de sus derechos, comoquiera que siempre había estado al cuidado de las dos mujeres; por tanto, era necesario el reconocimiento legal del vínculo entre la madre de crianza y la hija biológica de su compañera. Después de haber puesto de relieve que la Constitución de Colombia admite, reconoce y protege la diversidad de estructuras familiares, la Corte en ese caso acogió el recurso. En la Sentencia C-07 I/ I 5 la Corte declaró la inconstitucionalidad parcial de los artículos 64, 66 y 68 de la Ley Io9 8 de 2006. Con efectos erga omnes reconoció que, cuando el padre o la madre de crianza haya compartido el cuidado, la asistencia y la manutención de un menor con el padre o la madre biológicos, aunque sea del mismo sexo, se comprometen los derechos de los hijos en cuestión en caso de que haya normas que impidan el reconocimiento de un vínculo jurídico.

\section{Conclusiones}

La Corte Constitucional consideró que la adopción de hijos por parte de parejas del mismo sexo no pone en peligro el interés superior del menor ni compromete su salud física o mental ni su desarrollo armónico integral, como se desprende de la amplia etapa de investigación realizada y del examen efectuado del derecho comparado. A la misma conclusión podía llegarse estudiando los conceptos expresados en decisiones anteriores por parte de la misma Corte: por estas razones, la Corte Constitucional se pronunciaba sobre lo dispuesto por los citados artículos del Código de la Infancia y la Adolescencia y la ley sobre uniones maritales de hecho (Ley 54 de I990). Debido a que la exclusión del universo de adoptantes impuesta a las parejas del mismo sexo genera un déficit de protección de los niños y niñas y adolescentes en estado de abandono, lesionando el interés superior del menor, que tiene valor constitucional, y el derecho a tener una familia, el complejo normativo examinado resultó, según la Corte, violatorio del artículo 44 de la Constitución.

Se expresó así la Corte:

$[\mathrm{N}]$ o resulta constitucionalmente válido excluir a los menores de la posibilidad de ser adoptados por parejas del mismo sexo que conforman una familia y cumplen los requisitos para brindarles un entorno adecuado para su crecimiento integral. En otras palabras, privar a niños que carecen de un hogar estable de la posibilidad -de por sí altamente restringida- de hacer parte de una familia con el 
único argumento de que está integrada por una pareja del mismo sexo, a pesar de que se acreditan las condiciones para brindarles un entorno idóneo para su desarrollo armónico e integral, implica generar un déficit de protección que compromete su derecho a tener una familia y con ello el principio de interés superior del menor, que es en últimas el criterio que debe imperar en esta clase de decisiones. Como ya fue reseñado, la adopción de niños por personas con orientación sexual diversa, en general, y por parejas del mismo sexo, en particular, no afecta por sí misma el interés superior del menor ni compromete de manera negativa su salud física y mental o su desarrollo integral. En esa medida, no existe un criterio objetivo y razonable para restringir a los menores en situación de orfandad el derecho a tener una familia, o limitarlo únicamente a aquellas integradas por un hombre y una mujer. Negar a un menor en situación de abandono la posibilidad de hacer parte de una familia conformada por una pareja del mismo sexo, que está en capacidad y desea brindarle las condiciones para garantizar su desarrollo armónico e integral (amor, cuidado, apoyo, educación y demás aspectos relacionados con su crianza y el ejercicio pleno de sus derechos), no solo carece de fundamento constitucionalmente válido sino que implicaría obstaculizar la realización de su derecho a tener una familia, generando un déficit en su protección del principio de interés superior del menor.

La Corte también refiere datos estadísticos del Iсвғ que demuestran la insuficiencia del número de adopciones en Colombia: entre 20 Iо y 2014 el número de adopciones ha disminuido de forma significativa. Frente a los 3.058 menores adoptados en 20 Io se había pasado a los 2.7 I3, I.465, I. I 25 y 880 menores adoptados en los siguientes años hasta el 2014, experimentándose de forma evidente el déficit de adopciones de menores en el país, ya que sólo en 2014 aproximadamente 5.439 niños, niñas y adolescentes estaban en espera de una familia adoptiva, mientras que en aquel mismo año únicamente 880 niños fueron adoptados:

Así las cosas, la exclusión de las parejas del mismo sexo de la posibilidad de participar en procesos de adopción comporta un déficit de protección de los derechos de los menores que se encuentran en situación de orfandad, por cuanto si se acreditan dadas las condiciones para hacer parte de una familia su derecho se verá frustrado sin que exista una razón que lo justifique, distinta a la mera condición sexual de los adoptantes. En concepto de la Corte, reconocer que como familia constitucionalmente protegida las parejas del mismo sexo pueden participar en procesos de adopción, por supuesto si cumplen con los requisitos que prevé la ley para asegurar su formación integral, de ninguna manera supone hacer "experimentos de ingeniería social con los niños en situación de vulnerabilidad", como lo sostiene el Jefe del Ministerio Público. Por el contrario, empíricamente se ha demostrado que sí es posible llevar a cabo ese tipo de adopción sin afectar o poner en riesgo el interés superior del menor. Punto en el cual la Corte 
remite nuevamente a lo señalado en acápites precedentes, donde se explicó que la evidencia científica mayoritaria, sustentada en numerosas investigaciones empíricas, coincide en afirmar que la presencia de padres del mismo sexo en el núcleo familiar no afecta el interés superior del menor, su bienestar, salud física o mental, ni en general su desarrollo armónico e integral. En la misma dirección se encaminan las medidas legislativas de otros Estados, así como las decisiones de tribunales internos e internacionales, en donde siempre se ha tenido en cuenta la primacía de los derechos de los menores y la evidencia científica acopiada5.

En consecuencia, de frente a los artículos 64, 66 y 68 del Código de la Infancia y la Adolescencia y al artículo i de la Ley 54 de I990, la respuesta constitucional adecuada consistió en declarar la constitucionalidad condicionada en el sentido de que en virtud del interés superior del menor deben entenderse comprendidas en su ámbito de aplicación las parejas del mismo sexo que constituyan una familia.

\section{Para una crítica del self restraint}

La Corte añade que no tienen sentido las objeciones planteadas a un excesivo activismo de los jueces constitucionales no legitimados por una elección popular. En efecto, en un Estado constitucional como Colombia es tarea de los jueces proteger los derechos, en especial los de los grupos vulnerables, como los niños y niñas que no han podido ser acogidos en una familia debido al diseño normativo actualmente existente. En múltiples ocasiones, el juego democrático, que se atiene a la regla de la mayoría, excluye el reconocimiento de los derechos de ciertos grupos o sectores de la población que en general no tienen una significativa representación política. Eso es lo que, en buena medida, justifica el control de constitucionalidad como una forma de reforzar los derechos, en particular los derechos de las minorías.

Ciertamente la Corte no podría renunciar a proteger el interés superior del menor y a invocar una mera intervención del legislador:

Cuando la determinación del Tribunal implica una mejor garantía en el ejercicio de los derechos, especialmente de aquellos que tienen una protección constitucional reforzada, esta resulta inaplazable y no puede condicionarse a la decisión de otros órganos; debe ser de tal índole que logre una garantía efectiva e inmediata sobre el grupo vulnerable, en este caso los menores en situación de adoptabilidad. La Corte incumpliría entonces la función asignada por el Constituyente, y por ello del más alto origen democrático, si se limitara a exhortar al Legislador para superar el déficit de protección advertido para un segmento de

5 Cursiva fuera de texto. 
la población particularmente vulnerable. En el caso colombiano, por lo demás, no existe evidencia en el sentido de que el Congreso de la República tenga voluntad de remediar la situación. No hay constancia de iniciativas legislativas encaminadas a superar el déficit de protección que ha constatado esta Corte. Todo lo contrario. Además -solo a manera indicativa - una reciente encuesta elaborada por la Misión de Observación Electoral indica que el 71\% de los congresistas se opone a la adopción de menores por parte de parejas del mismo sexo y, por contera, a aquella medida que serviría al propósito de enmendar el desmedro al interés superior del niño. Esta circunstancia sugiere, cuando menos, que la forma de superar el déficit de protección de los menores en situación de abandono, directamente desde el seno del propio Congreso de la República, se encuentra en el corto plazo seriamente comprometida, ante lo cual el juez constitucional no puede asumir una actitud silente.

\section{Puntos de reflexión}

La Corte amplió en 2007 el ámbito de la ley sobre uniones maritales de hecho a las parejas homosexuales, sin que a ello hubiera seguido una extensión similar de la ley que regula la adopción con el propósito de permitir a las parejas de hecho, contempladas en la ley misma, el derecho de solicitar la adopción independientemente de su orientación sexual. Frente a una práctica negativa y a la inercia culpable del Parlamento -significativamente expresada por la falta de aprobación del matrimonio igualitario o de institución equivalente en el plazo fijado por la sentencia de 20 I I- intervino la Corte en materia de adopción, primero extendiendo a parejas de hecho homosexuales la Stepchild Adoption mediante Sentencia C-07I/I 5, y luego, con la sentencia objeto de este comentario, la adopción conjunta. De manera significativa, la presente decisión, tomada por una Corte renovada en la composición respecto de aquella de la Sentencia C-07 I/ 5 -la cual había considerado que las disposiciones que impedían la adopción conjunta por parte de parejas homosexuales no violaban la igualdad de tales las parejas-, evita contradecirla aplicando otro parámetro constitucional, el del interés superior del menor de frente a un dramático descenso en el número de las adopciones en Colombia. De hecho, también de cara a los datos estadísticos, el aumento de las oportunidades para los menores abandonados desarrolla el deber del Estado -de rango constitucional- de garantizarles el derecho a una familia.

A las significativas aperturas de la Corte (en nada comparables a las de su homóloga italiana) sobre los derechos civiles de los homosexuales, y sobre los derechos específicos (fiscales, sociales, incluso sobre la protección penal del incumplimiento de obligaciones alimentarias) podemos comparar la actuación de la Corte Suprema de Estados Unidos, absolutamente indiferente sobre este punto en lo que respecta a la "discreción del legislador" en la materia. 
En efecto, si un derecho fundamental existe y no está protegido por el legislador, no hay otro camino que el pronunciamiento de inconstitucionalidad, que ahora, a nuestro juicio, transcurridos inútilmente seis años desde la Sentencia I 38/ Io, es prioritario también en Italia. Ni vale alegar la existencia de la Ley italiana número 76 del 20 de mayo de 2016 , que por primera vez ha regulado las uniones maritales para las parejas homosexuales en los numerales I a 35 de su artículo único. Esta ley reconoce a dichas parejas derechos bastante menores. En particular, el numeral 20 dispone que las palabras "cónyuge" y "cónyuges" deben aplicarse también a los compañeros permanentes en las disposiciones legales, reglamentarias y de contrato colectivo donde ellas aparezcan, pero excluye expresamente las normas del Código Civil (que disponen, p. ej., sobre el parentesco y la afinidad o sobre las sucesiones); y, sobre todo, excluye las normas de la Ley número I 84 del 4 de mayo de I983 en materia de adopción, excluyendo así a las parejas de personas homosexuales de la adopción: lo que tiene además un impacto dramático en cientos de parejas de mujeres lesbianas que en Italia han decidido tener hijos mediante inseminación asistida -realizada en el extranjero por la prohibición de la ley italiana-, y que han criado juntas a sus hijos desde su nacimiento, con la consiguiente imposibilidad de constituir una relación parental por efecto de la ley o por adopción plena en cabeza de la madre no biológica.

Por lo demás, la ley no reconoce a estas familias como familias (como, en cambio, lo impondría el TEDH en el caso Schalk and Kopf v. Austria), sino como meras "formaciones sociales específicas" según el artículo 2 de la Constitución, a la par de una asociación deportiva. Una ley que no protege a los hijos criados conjuntamente por estas parejas y procreados y concebidos mediante inseminación asistida en el extranjero ${ }^{6}$ deja en un limbo inaceptable y pone en riesgo al menor de sufrir serios traumas en su continuidad afectiva y educativa, cuandoquiera que la madre biológica llegase a faltar, o en caso de que la pareja se separase, debido a los obstáculos a la visita de los hijos, que son tan frecuentes en Italia. La intervención del Gobierno, que quien escribe considera bastante meritoria, con el respaldo a la Ley 76 de 2016 , vio sacrificado el artículo 5 del proyecto de ley, que habría ampliado a estas parejas la adopción particular por vía del artículo 44 d) de la Ley I $84 / 83^{[7]}$. Pero si el ejecutivo tiene los votos que tiene, no obstante su empeño, no es menos cierto que el derecho de los niños y niñas a una familia subsiste, no por vía de hecho, sino sancionado por la ley.

Sin embargo, la Corte de Casación, confirmando una serie de sentencias del Tribunal de Menores de Roma, en decisión del 26 de mayo - 22 de junio

6 La ley italiana no permite todavía la inseminación asistida heteróloga de una mujer no casada: artículo 5 de la Ley número 40 del ig de febrero de 2004.

7 Ley sobre el derecho a la continuidad afectiva de los niños y niñas en custodia familiar, artículo 44.I: "Los menores también pueden ser adoptados cuando no concurren las condiciones del inciso I del Artículo 7: [...] d) Cuando haya una constatada imposibilidad de custodia preadoptiva". 
de 2016 , número I 2962, ha afirmado que la adopción particular, prevista en el artículo 44 letra d) de la Ley i $84 / 8_{3}$, puede ser decretada en favor de los hijos de estas parejas. Específicamente, indica que la norma que permite la adopción particular en caso de imposibilidad de una custodia preadoptiva no puede ser interpretada en sentido restrictivo -como solicitaba la Procura Generale della Reppublica presso la Suprema Corte di Cassazione-, esto es, en el sentido de incluir sólo aquellos eventos de impedimentos "de hecho", como el caso del niño que debe vivir permanentemente en un hospital, sino también los impedimentos "de derecho", como en el caso concreto, donde la pareja de la madre biológica no puede solicitar la custodia preadoptiva, no sólo porque el menor no está abandonado, sino también porque no está casada, como requeriría el artículo 6 de la Ley i 84 . Finalmente, la absurda existencia de una norma como la del artículo 55 de la Ley I $84 / 83^{[8]}$, que excluye la extensión del vínculo de parentesco a los parientes del adoptante -que así no se convierten en abuelos, tíos, primos del adoptado (y, más grave aún, en caso de adopción cruzada de los hijos biológicos de dos compañeros permanentes, los hijos adoptados no adquieren lazos de hermandad entre ellos)-, afecta en no pocos aspectos el derecho de estos niños a una familia, sin una justificación racional. Lo que vale, además, como es evidente, para todos los menores a quienes se aplique el artículo 55.

Debe ser superada, con apoyo en la evidencia científica (entre otras, señalada en sendas notas al pie en la monumental sentencia objeto de este comentario, y que bien puede ser fuente de conocimiento sobre este tipo de estudios para los operadores italianos), la idea preconcebida según la cual dos homosexuales no pueden ser buenos padres y que, por tanto, deban ser excluidos de la adopción conjunta, como lo dispone el artículo 6 de la Ley r84/83. La Corte Constitucional casi nunca hace uso de una etapa de investigación -a pesar de tener la facultad para ello-, de modo que la única esperanza al parecer puede provenir de las deliberaciones más profundas de las cortes supranacionales. No obstante, una decisión valiente podría afirmar que, en igualdad de condiciones, y gracias a la función social (de mantener, instruir y educar a los hijos) garantizada por una pareja homosexual estable de potenciales adoptantes, sujetos al escrutinio de idoneidad del tribunal de menores (con anterioridad a la custodia preadoptiva y a su finalización), no puede existir una disciplina diferenciada, so pena de lesionar el derecho a la igualdad.

Finalmente, como se mencionó también por el TEDH, en el caso Paradiso y Campanelli, y como se resolvió sin demasiados problemas por la Corte Constitu-

8 El artículo 55 de la Ley I $84 / 83$ establece que se aplican las disposiciones de los artículos 293, 294, 295, 299, 300 y 304 del codice civile. El artículo 300 del código civil establece: "El adoptado conserva todos los derechos y deberes frente a su familia de origen, salvas las excepciones establecidas en la ley. La adopción no produce ninguna relación civil entre el adoptante y la familia del adoptado, ni entre el adoptado y los parientes del adoptante, salvas las excepciones establecidas por las leyes". 
cional colombiana, los hijos nacidos por maternidad por sustitución, que tengan un certificado de nacimiento y un estatus legítimo, no pueden ser privados de sus padres posteriormente al nacimiento por el solo hecho de la modalidad de su nacimiento. La etología demuestra que los pequeños se sienten hijos de quien se ocupa de ellos (y aquí queremos reenviar a los espléndidos trabajos de Konrad Lorenz). Dondequiera que se considere existente un vínculo intrauterino entre la mère porteuse y el niño, un segundo y más profundo vínculo afectivo se forma por la prestación de cuidados al recién nacido. Si se privilegiara el primero, en caso de alejamiento posterior al nacimiento, por parte de los padres, el niño sufriría un doble daño, como consecuencia de lo ilusorio del hallazgo y de su devolución a la mère porteuse. Como se evidencia en la Sentencia colombiana SU-696/ I 5, las autoridades colombianas no sólo están en el deber de acoger un certificado de nacimiento válido, sino que además, como consecuencia, se ha proveído a incluir, en la casilla "padre" y "madre", dos progenitores masculinos, y, con posterioridad al fallo, la Registraduría Nacional del Estado Civil ha elaborado un nuevo formato de inscripción en el Registro Civil en el que es posible la inscripción de los hijos de parejas del mismo sexo9.

¿Qué es lo que importa al final de cuentas? La realidad es que existen diversas familias, todas dignas de protección constitucional. Estos niños y niñas, realmente existentes, no pueden sufrir perjuicio porque la opinión de algunos en Italia cree todavía en la ficción de reglas morales (que se pueden o no compartir, pero no son personas, no son realidades, son solo pensamientos) que condenan la orientación sexual de sus padres o las modalidades en las que ellos vinieron al mundo.

9 Ver Registraduría Nacional del Estado Civil, Circular o24 del 8 de febrero de 20 I 5 . 